\title{
Gender specific pattern of left ventricular cardiac adaptation to hypertension and obesity in a tertiary health facility in Nigeria
}

\author{
*Akintunde AA ${ }^{1,3}$, Oladosu $\mathrm{Y}^{2}$, Opadijo $\mathrm{OG}^{1}$
}

1.Division of Cardiology, Ladoke Akintola University of Technology Teaching Hospital, Osogbo. Nigeria. 2.Department of Medicine, Federal Medical Centre, Ido-Ekiti, Nigeria.

3.Goshen Heart Clinic, Osogbo, Nigeria

\begin{abstract}
Background: Cardiac adaptation to hypertension and obesity may be related to many factors such as race, gender and haemodynamic status. Some gender specific associations with left ventricular structure and function have been described among Caucasians.

Objectives: To describe the sex specific pattern of left ventricular adaptations to obesity and hypertension among Nigerians. Methodology: It was a cross sectional study carried out at LAUTECH Teaching Hospital,

Osogbo, Nigeria. 313 subjects had full echocardiography performed. Participants were divided into four groups: normal, obese, hypertensives and obese-hypertensives. Indices of LV adaptation were compared between the groups. SPSS 16.0 was used for analysis.

Results: Relative to normal subjects, LV mass (LVM), LV mass index (LVMI) and wall thickness were significantly higher among hypertensive men and obese hypertensive men. They were similar between normal and obese men. However, LVM, LVMI and wall thickness were increased among obese women compared to normal women while they were similar among obese, hypertensive and obese-hypertensive women. Men with concurrent obesity and hypertension presented with a further increase of LVM and wall thickness above values in the merely obese or hypertensive subjects. Female obesehypertensive seem to present more with eccentric hypertrophy than male obese-hypertensive subjects $(17.2 \%$ vs. $9.1 \%$ respectively, $\mathrm{p}<0.05)$ while male obese-hypertensive seem to present more with concentric hypertrophy $(54.5 \%$ vs. $43.1 \%$ respectively, $\mathrm{p}>0.05$ ) than female obese-hypertensive subjects.

Conclusions: Structural, functional and geometric LV adaptation to obesity and hypertension varies between the two genders among Nigerians. The impact of isolated obesity on LV adaptation in women appears very significant.
\end{abstract}

Key words: gender, obesity, hypertension, LV geometry, left ventricular hypertrophy

African Health Sciences 2013; 13(3): 595 - 600 http://dx.doi.org/10.4314/ahs.v13i3.11

\section{Introduction}

Hypertension and obesity are both associated with significant changes in cardiac structure and function which have been well described in the literature. ${ }^{1,2}$ The prevalence of left ventricular hypertrophy $(\mathrm{LVH})$ rises with increasing blood pressure, age and obesity $^{2}$. Hypertension and obesity are the commonest cardiovascular risk factors worldwide ${ }^{1,2,3}$. LVH and alteration of LV geometry are associated with hypertension and obesity both individually and are at least additive when they occur

\begin{tabular}{|l|}
\hline *Corresponding author: \\
Dr. Akintunde A Adeseye \\
Division of Cardiology \\
Ladoke Akintola University of Technology \\
Teaching Hospital \\
P.O. Box 3238 \\
Osogbo, Nigeria. \\
Tel No+234-803-393-2076 \\
E-mail:ia kint und e $2 @$ y a h o o.c o m \\
aakintunde@lautech.edu.ng.
\end{tabular}

African Health Sciences Vol 13 Issue 3 September 2013 together ${ }^{4,5}$. LVH is independently associated with increased cardiovascular mortality, congestive heart failure, renal failure and coronary heart disease ${ }^{6,7}$. Abnormal LV geometry is equally an important prognostic factor in hypertension and obesity. Eccentric hypertrophy has been associated with the early stage of impaired systolic dysfunction while other abnormal geometric patterns have been associated with increased cardiovascular morbidity and mortality ${ }^{1,8}$. Association with race have not been fully described. Factors which influence cardiac adaptation to hypertension include age, duration of hypertension, systolic and diastolic blood pressure, gender, drugs and presence of other cardiovascular risk factors such as obesity. Cardiac adaptation in hypertension and obesity occur as a result of pressure and volume changes in order to maintain haemodynamic balance ${ }^{8}$. Some gender specific associations with left ventricular structure and function have been described among Caucasians. Many Authors suggests that women are at increased 
risk due to $\mathrm{LVH}$ and that cardiac adaptation to hypertension and obesity are sex-dependent 9,10 Norton et al. ${ }^{11}$ showed that obesity is associated with additional impact on left ventricular mass among Africans. However, information on gender specific pattern of cardiac adaptation to obesity and hypertension among Nigerians are scarce.

Therefore, this study aimed at describing the gender specific pattern of cardiac adaptation to hypertension and obesity among Nigerians.

\section{Methods}

The study was a cross sectional study. The study population consisted of 245 hypertensive subjects and 68 normotensive controls. The normal subjects were recruited consecutively from patients' relatives and hospital staff who willingly gave their consent to participate. They were hypertensive subjects recruited consecutively at the cardiology clinic of Ladoke Akintola University of Technology Teaching Hospital, Osogbo, Nigeria.

The inclusion criteria was an adult $>18$ years of age with diagnosis of hypertension being followed up at the cardiology clinic of our hospital. Subjects with clinical heart failure, diabetes and renal disease were excluded from the study. All subjects had history taking, physical examination and echocardiography done. Blood pressure was measured with Accosson sphygmomanometer on the right arm of each subject after he/she had been sitting for at least 5 minutes. Hypertension was diagnosed according to standardized protocols as blood pressure $>140 / 90 \mathrm{mmHg}$ and/or the use of antihypertensive therapy ${ }^{4}$.

The weight (in kilograms) of each participant was measured using standard weighing scale in light clothing with the shoes off. The height (in meters) was taken using a stadiometer. Body mass index (BMI) was determined by dividing the weight (in kilograms) by the square of the height (in meters).

Obesity was defined according to the National Institute of Health criteria as BMI $>27.8 \mathrm{~kg} /$ $\mathrm{m} 2$ for men and $27.3 \mathrm{~kg} / \mathrm{m} 2$ for women. 12 Subjects with history of heart failure, diabetes mellitus, renal failure and cerebrovascular disease were excluded from the study.

\section{Echocardiography}

Echocardiography was performed according to the recommendation of the American Society of Echocardiography (ASE) 13 using a SUIS Apogee ultrasound with $3,5 \mathrm{MHz}$ cardiac transducer with the patient in the left lateral decubitus position. Two dimensional guided Mmode was used for measuring chamber and wall dimensions [posterior (PWTd) and interventricular septal wall thickness in diastole (IVSd)] using the leading edge to leading edge technique. The left ventricular mass was derived using the Devereux modified ASE cube formula 14 which has been shown to correlate with necropsy findings. LV mass $(\mathrm{g})=0.8\{1.04$ (IVSd + LVIDd + PWTd) 3 - (LVIDd) 3$\}+0.6$.

LV mass was indexed to body surface area to obtain the left ventricular mass index (LVMI). LVH was considered present if the left ventricular mass index is $>134 \mathrm{~g} / \mathrm{m} 2$ and $110 \mathrm{~g} / \mathrm{m} 2$ for males and females respectively.14 Relative wall thickness was derived by $2 \times$ PWT/LVIDd. Normal RWT was defined as $<0.45$. Normal geometry was defined as normal left ventricular mass and normal relative wall thickness. Concentric remodelling was defined as increased relative wall thickness (RWT> 0.45) and normal left ventricular mass. Concentric hypertrophy was defined as increased relative wall thickness and increased left ventricular mass.

Eccentric hypertrophy was defined as increased left ventricular mass with normal relative wall thickness.3,14 Study subjects were divided into four subgroups: normal subjects (not hypertensive and not overweight), obese subjects (having elevated BMI but not hypertensive), hypertensive subjects (hypertension with normal BMI) and obesehypertensive subjects (having increased BMI and hypertension coexisting together).

\section{Analysis}

Statistical anlysis was done using the Statistical package for Social Sciences 16.0 (Chicago Ill.) Categorical variables were expressed as proportion (percentages) while continuous variables were expressed as means \pm standard deviation. Independent t-test and analysis of variance were used for comparism between continuous variables while fisher's exact test and chi square tests were used for comparison between categorical variables. Values were considered statistically significant when $\mathrm{p}<0.05$. Institutional Ethical approval was obtained for the study.

\section{Results}

The demographic characteristics of male and female participants are shown in table 1. 
They were similar in age distribution. This is shown in table 1. Hypertensive and normal control subjects were also similar in age and body surface area. They were well matched in age and gender distribution. Expectedly, systolic diastolic blood pressure, left ventricular mass, body mass index and relative wall thickness were higher among hypertensive subjects than control subjects. Men and women participants were similar in age, systolic and diastolic blood pressure and body mass index. Obesity was commoner among women than men (40.9 vs. $27.4 \%$, $\mathrm{p}<0.05$ respectively). Though the mean LVMI and interventricular septal wall dimension was significantly higher among men, the frequency of occurrence of LVH was similar among men and women (46.3\% vs. $47.7 \%$ respectively, $\mathrm{p}>0.05)$ as shown in table 2 . Normal women showed lower values in most echocardiographic parameters except relative wall thickness which was higher among women than men.

Table 1: Clinical and demographic parameters based on gender distribution

\begin{tabular}{llll}
\hline Variables & Males (164) & Females (149) & $\mathrm{p}$ \\
\hline Age (years) & $56.8 \pm 11.5$ & $56.0 \pm 11.4$ & 0.519 \\
SBP(mmHg) & $142.5 \pm 23.7$ & $141.4 \pm 25.0$ & 0.689 \\
DBP(mmHg) & $87.2 \pm 12.0$ & $86.9 \pm 12.9$ & 0.827 \\
BMI $(\mathrm{kg} / \mathrm{m} 2)$ & $25.4 \pm 5.1$ & $26.4 \pm 5.5$ & 0.084 \\
LVMI $(\mathrm{g})$ & $127.1 \pm 48.1$ & $115.0 \pm 55.8$ & $0.045^{*}$ \\
LVH $(\mathrm{n})$ & $76(46.3 \%)$ & $71(47.7 \%)$ & 0.859 \\
RWT & $0.56 \pm 0.56$ & $0.50 \pm 0.25$ & 0.294 \\
PWT (mm) & $12.9 \pm 12.3$ & $12.3 \pm 2.7$ & 0.351 \\
IVSD (mm) & $13.7 \pm 10.7$ & $10.7 \pm 8.2$ & $0.038^{*}$ \\
Obesity (n) & $45(27.4 \%)$ & $61(40.9 \%)$ & $0.02^{*}$ \\
Normals (n) & $26(15.9 \%)$ & $26(17.4 \%)$ & $0.001^{*}$ \\
\hline
\end{tabular}

*-statistically significant SBP-systolic blood pressure, DBP-diastolic blood pressure, BMI-body mass index, LVMI-left ventricular mass index, LVH- left ventricular hypertrophy, RWT-relative wall thickness, PWT-posterior wall thickness in diastole, IVSD-interventricular septal dimension in diastole

Table 2: Clinical and echocardiographic profile among men and women in the study population

\begin{tabular}{|c|c|c|c|c|c|c|}
\hline Males & Variable & $\begin{array}{l}\text { Normal } \\
(\mathrm{n}=26)\end{array}$ & $\begin{array}{l}\text { Obese } \\
(n=12)\end{array}$ & $\begin{array}{l}\text { Hypertensive } \\
(\mathbf{n = 9 3})\end{array}$ & $\begin{array}{l}\text { Hypertensive } \\
\text { Obese }(\mathbf{n}=33)\end{array}$ & $\mathbf{P}$ \\
\hline & $\mathrm{SBP}(\mathrm{mmHg})$ & $124.8 \pm 12.9$ & $124.2 \pm 12.9$ & $150.0 \pm 25.3^{*} \dagger$ & $147.1 \pm 17.2^{*} \dagger$ & 0.000 \\
\hline & $\mathrm{EF}(\%)$ & $70.8 \pm 6.7$ & $75.8 \pm 7.6$ & $67.2 \pm 17.2$ & $70.4 \pm 12.4$ & 0.083 \\
\hline & $\operatorname{IVSD}(\mathrm{mm})$ & $11.9 \pm 4.4$ & $10.7 \pm 3.1$ & $13.1 \pm 3.6^{*} \dagger$ & $17.6 \pm 12.2^{* *+\ddagger}$ & 0.171 \\
\hline & PWT (mm) & $10.9 \pm 1.7$ & $10.4 \pm 2.0$ & $12.5 \pm 9.9 * \dagger$ & $16.2 \pm 12.3^{* *}+\ddagger$ & 0.457 \\
\hline & RWT & $0.41 \pm 0.06$ & $0.46 \pm 0.06^{*}$ & $0.55 \pm 0.45^{* *} \dagger$ & $0.70 \pm 0.97 * *+\ddagger$ & 0.0381 \\
\hline & LVMI (g/m2) & $95.2 \pm 47.1$ & $99.0 \pm 31.5$ & $129.1 \pm 47.0 *+$ & $155.1 \pm 45.2^{* *}+\ddagger$ & 0.002 \\
\hline \multirow{7}{*}{ Female } & & $(n=26)$ & $(n=10)$ & $(n=61)$ & $(n=52)$ & \\
\hline & $\mathrm{SBP}(\mathrm{mmHg})$ & $122.6 \pm 15.1$ & $124.0 \pm 4.6$ & $143.6 \pm 24.5^{*} \dagger$ & $148.9 \pm 25.5^{*} \dagger$ & 0.000 \\
\hline & $\mathrm{EF}(\%)$ & $70.0 \pm 17.1$ & $57.8 \pm 15.9^{*}$ & $68.6 \pm 14.4 * \dagger$ & $70.4 \pm 12.4 \dagger$ & 0.356 \\
\hline & $\operatorname{IVSD}(\mathrm{mm})$ & $10.5 \pm 3.1$ & $12.8 \pm 0.7 *$ & $14.1 \pm 12.2^{* * \dagger}$ & $12.2 \pm 2.8^{*}$ & 0.312 \\
\hline & PWT (mm) & $9.8 \pm 3.5$ & $11.3 \pm 0.3^{*}$ & $10.7 \pm 2.6^{*}$ & $11.0 \pm 2.4^{*}$ & 0.292 \\
\hline & RWT & $0.40 \pm 0.12$ & $0.48 \pm 0.11^{*}$ & $0.49 \pm 0.14^{*}$ & $0.55 \pm 0.36^{* *} \dagger \ddagger$ & 0.286 \\
\hline & LVMI (g/m2) & $94.4 \pm 45.9$ & $113.6 \pm 32.4^{*}$ & $120.9 \pm 71.1^{*}$ & $111.2 \pm 36.9^{*}$ & 0.102 \\
\hline
\end{tabular}

\footnotetext{
$*$ vs. normals $<0.05$, **- vs. normals $<0.01$, † vs. Obese $\mathrm{p}<0.05 \ddagger$ - vs. hypertensives $\mathrm{p}<0.05$ SBP-systolic blood pressure, EF-ejection fraction, IVSD-interventricular septal dimension in diastole, PWT-posterior wall thickness in diastole, LVM-left ventricular mass, LVMI-left ventricular mass index, RWT-relative wall thickness, ht-height
} 
Relative to normal subjects, LVM, LVMI, PWT, and IVSD were significantly higher among hypertensive men and obese hypertensive men. They were similar between normal and obese men. Also, LVM, PWT and IVSD were increased among obese women compared to normal women while they were similar among obese, hypertensive and obese- hypertensive women. Among men, RW'T increased among obese men compared to normals and further increased among hypertensive and obese hypertensive men. The increment in RWT was however less for females as shown in table 3 .

Table 3: Distribution of LV geometric pattern and LVH among study participants

\begin{tabular}{|c|c|c|c|c|c|c|}
\hline & Variable & Normal & Obese & Hypertensive & Hypertensive & $\mathbf{P}$ \\
\hline \multirow[t]{6}{*}{ Males } & & $(n=26)$ & $(n=12)$ & $(n=93)$ & Obese $(n=33)$ & \\
\hline & $\begin{array}{l}\text { Normal } \\
\text { Geometry }\end{array}$ & $20(76.9 \%)$ & $6(50 \%)$ & $23(24.7 \%)$ & $2(6.1 \%)$ & $0.000 *$ \\
\hline & $\mathrm{CR}$ & $1(3.8 \%)$ & 0 & $28(30.1 \%)$ & $10(30.3 \%)$ & \\
\hline & $\mathrm{CH}$ & $3(11.5 \%)$ & $6(50 \%)$ & $28(30.1 \%)$ & $18(54.5 \%)$ & \\
\hline & $\mathrm{EH}$ & $2(7.7 \%)$ & 0 & $14(15.1 \%)$ & $3(9.1 \%)$ & \\
\hline & High LVMI & $\begin{array}{l}5(19.2 \%) \\
(\mathrm{n}=26)\end{array}$ & $\begin{array}{l}6(50 \%) \\
(\mathrm{n}=10)\end{array}$ & $\begin{array}{l}48(51.6 \%) \\
(n=61)\end{array}$ & $\begin{array}{l}21(63.6 \%) \\
(n=52)\end{array}$ & $0.000 *$ \\
\hline \multirow{5}{*}{ Female } & $\begin{array}{l}\text { Normal } \\
\text { Geometry }\end{array}$ & $20(76.9 \%)$ & $3(30 \%)$ & $17(27.9 \%)$ & $13(25.0 \%)$ & $0.000^{*}$ \\
\hline & $\mathrm{CR}$ & $3(11.5 \%)$ & $2(20 \%)$ & $17(27.9 \%)$ & $7(13.5 \%)$ & \\
\hline & $\mathrm{CH}$ & $3(11.5 \%)$ & $1(10 \%)$ & $16(26.2 \%)$ & $22(42.3 \%)$ & \\
\hline & $\mathrm{EH}$ & 0 & $4(40 \%)$ & $11(11.8 \%)$ & $10(19.2 \%)$ & \\
\hline & High LVMI & $3(11.5 \%)$ & $5(50 \%)$ & $29\left(31.2^{\circ} \%\right)$ & $34(65.4 \%)$ & $0.006^{*}$ \\
\hline
\end{tabular}

*-statistically significant.

CR-concentric remodelling, $\mathrm{CH}$-concentric hypertrophy, EH-eccentric hypertrophy

\section{Discussion}

This study showed that LVM and RWT were significantly higher among male obese hypertensive subjects than male hypertensive subjects. Although, LVM was similar among normal and obese male participants, the relative wall thickness was significantly higher among obese men than normal men. Obese women had significantly higher LVM and relative wall thickness than normal controls while mean LVM was similar among obese, hypertensive and obese-hypertensive females compared to males. There are therefore gender specific associations in left ventricular adaptation to obesity and hypertension among Nigerians similar to what has been reported among other populations $s^{1,9,10}$. In this study, obesehypertensive men seem to have an additive effect on left ventricular mass and wall thickness dimensions when obesity coexisted with hypertension while obesity seem to have a high impact on left ventricular mass among women comparable to the impact of hypertension. Obese women equally had significant increase in chamber wall dimension compared to normal women.

Hypertension also led to increase in mean LV wall dimensions, LV mass and relative wall thickness similar to what was obtained by obesity on these parameters. This suggests that obesity in women have significant impact on LV adaptation and that of normal women is likely to be more. As the prevalence of obesity increase worldwide, various cultural and traditional practices encourage obesity especially among women which will consequently lead to LV remodelling.

The attendant significant impact on LV adaptation among Nigerian women may herald an increase in abnormal left ventricular geometry and left ventricular hypertrophy thereby predisposing Nigerian women to increased cardiovascular risk. $\mathrm{LVH}$ is an important cardiovascular risk factor.LVH and abnormal left ventricular geometry are associated with increase in incidence of heart failure, cardiac arrhythmias, sudden cardiac death and coronary heart disease $\mathrm{e}^{4,7}$.

The prevalence of LVH was lower among women compared to men among normals, obese and hypertensive subjects. This is in agreement with other studies except among obese - hypertensive women with a higher prevalence of LVH similar to what was obtained among obese-hypertensive males $^{7,10}$. This was despite the fact that obesity had significant impact on LV structure and geometry especially among obese females. The cut off used in this study to diagnose LVH may not have been very appropriate for this population. The use of a lower cut off value to diagnose LVH among women will result in a higher prevalence of $\mathrm{LVH}$ compatible

African Health Sciences Vol 13 Issue 3 September 2013 
with the impact demonstrated by obesity on LV structure and geometry among women in this study. Other authors have also suggested that LVH criteria may not be universally appropriate for different population ${ }^{15}$. The pattern of LV geometric adaptation was somewhat similar among the two genders. However, there are some differences: 6\% of obese-hypertensive men have normal geometry, compared to $25.0 \%$ of obese hypertensive women. Female obese hypertensives seem to present more with eccentric hypertrophy while male obesehypertensives seem to present more with concentric hypertrophy. Eccentric hypertrophy has been linked to adverse cardiovascular prognosis in heralding a progressive decline in LV systolic function. The prognostic implications of this suggests that female obese hypertensive subjects and may be at an increased risk of progressive LV systolic dysfunction as a result of coexistence of obesity and hypertension than their male counterparts due to the association with eccentric hypertrophy ${ }^{16,17}$. The prevalence of abnormal left ventricular geometry was higher among obese-hypertensive men than obesehypertensive women with a higher frequency of concentric LVH. Concentric LVH is an adverse cardiac remodelling associated with increase in risk of coronary heart disease, arrhythmia and sudden cardiac death due to increase in both left ventricular mass and relative wall thickness with myocardial ischaemia.

Some studies among Caucasians have suggested that LV response to obesity and hypertension is stronger in females than males ${ }^{16,17}$. Others have however demonstrated that the prevalence of hypertensive complications may be less among women than $\operatorname{men}^{18,19}$. The decrease in risk is primarily due to a reduced incidence of coronary heart disease (which is only one-half that in men at the same blood pressure). Also, a greater BP load seems to be required to produce cardiovascular injury in women ${ }^{20}$.

Women have been shown to have a different haemodynamic profile (matched for blood pressure, race and age) with a lower cardiac output and systemic vascular resistance both by $10 \%$ each compared to males. Women also have a wider pulse pressure and a faster heart rate. The pattern of BP increase with exercise is about two-third of that which obtains in men $^{21}$. Premenopausal women also have less effective baroreflex blood pressure buffering than men leading to less effective blood pressure regulation in women in response to vasoactive drugs and acute stress $^{22}$. The lower systemic vascular resistance seem to minimize vascular injury leading to reduction in prevalence of stroke, coronary heart disease and heart failure. The pathophysiologic mechanism responsible for the haemodynamic differences noticed is not well known but oestrogen have been postulated to play a part. However, in the presence of obesity and/or hypertension, many of these haemodynamic changes are likely altered leading to increase in cardiovascular risk equivalent or that even surpass their male counterpart. The association of menopause, where obesity among women is more common also adds to this argument as postmenopausal women have been shown to have increased cardiovascular risk. Absolute benefit from antihypertensive treatment such as on $\mathrm{LVH}$ regression and other cardiovascular end points have been shown to be less in women due to the lower number of recorded events if left untreated although women derive substantial cardiovascular protection equally as men in antihypertensive therapy in major cardiovascular trials ${ }^{18,23,24}$. Therefore, early control of obesity among women even before menopause is much likely to lead to significant reduction in cardiovascular risk among women in addition from the specific benefit in population health control.

\section{Conclusion}

This study showed an additional impact of obesity on LV adaptation among non hypertensive women compared to men and a higher prevalence of eccentric hypertrophy among obese hypertensive women while concentric hypertrophy predominates among obese-hypertensive men. With the continuous increase in prevalence of obesity world-wide especially among women, CVD risk among women may therefore rise significantly. Therefore implementation of primary and secondary preventive strategies may reduce the impact of obesity on CVD especially in obese women. The limitation of this study is that it is an hospital based study and therefore the outcome might not be exactly what is obtainable in the population. Also the study design does not categorically identify the causality between the gender specific differences in cardiac adaptation to hypertension.

\section{References}

1. Morse SA, Bravo PE, Morse MC, Reisin E. The heart in obesity-hypertension. Expert Rev Cardiovasc Ther. 2005;3(4):647-658.

2. Aje A, Adebiyi AA, Oladapo OO, Dada A, Ogah OS, Ojji DB, Falase AO. Left ventricular geometric 
patterns in newly presenting Nigerian hypertensives: an echocardiographic study. BMC Cardiovasc Disord.2006;6:4.

3. Ruilope LM, Schmieder RE. Left ventricular hypertrophy and clinical outcomes in hypertensive patients. Am J Hypertens. 2008 ;21(5):500-508.

4. Chobanian AV, Bakris GL, Black HR, Cushman WC, Green LA, Izzo JL Jr, et al. for the National High Blood Pressure Education Program Coordinating Committee. Seventh report of the Joint National Committee on Prevention, Detection, Evaluation and Treatment of High Blood Pressure JNC VII. Hypertens. 2003;12:12061252.

5. De Simone G, Devereux RB, Roman MJ, Alderman MH, Laragh JH. Relation of obesity and gender to left ventricular hypertrophy in normotensive and hypertensive adults. Hypertension 1994;23:600-606.

6. Akintunde AA, Familoni OB, Akinwusi PO, Opadijo OG. Relationship between left ventricular geometric pattern and systolic and diastolic function in treated Nigerian hypertensives. Cardiovasc J Afr. $2010 ; 21(1): 21-25$.

7. Verdecchia P, Porcellati C, Reboldi G, Gattogigio R, Borgioni C, Pearson TA, et al. Left ventricular hypertrophy as an independent predictor of acute cerebrovascular events in essential hypertension. Circulation 2001;104(17):2039-2044.

8. Cohn JN; Ferrari R; Sharpe N, Cardiac remodelling-concepts and clinical implications: a consensus paper from an international forum on cardiac remodelling. Behalf of an International Forum on Cardiac Remodelling. I Am Coll Cardiol $2000 ; 35(3): 569-582$.

9. Krumholz HM, Larson M, Levy D. Sex difference in cardiac adaptation to isolated systolic hypertension. Am J Cardiol 1993;72(3):310-313.

10. Celentano A, Palmieri V, Arezzi E,Mureddu GF, Sabatella M,Di Minno G, et al. Gender differences in left ventricular chamber and midwall systolic function in normotensive and hypertensive adults. J Hypertens. 2003;21(7):1415-1423.

11. Norton GR, Majane OH, Libhaber E, Maseko MJ, Makaula S, Libhaber C,et al. The relationship between blood pressure and left ventricular mass index depends on an excess adiposity. J Hypertens. 2009;27(9):1873-1883.

12. National Institute of Health Consensus Development Panel on Health implications of obesity. Ann Intern Med. 1991;114:202-209.

13.Sahn DJ, DeMaria A, Kisslo J, Weyman A. Recommendations regarding quantitation in Mmode echocardiography: results of a survey of echocardiographic measurements. Circulation 1978, 58:1072-1083.

600
14. Devereux RB, Alonso DR, Lutas EM, Gottlieb GJ, Campo E, Sachs I, Reichek N. Echocardiographic assessment of left ventricular hypertrophy: comparison to necropsy findings. Am J Cardiol 1986, 57:450-458

15. Abergel E, Tase M, Bohlender J, Menard J, Chatellier G. Which definition for echocardiographic left ventricular hypertrophy? Am J Cardiol. 1995 ;75(7):498-502.

16. Gerdts E, Zabalgoitia M, Björnstad H, Svendsen TL, Devereux RB. Gender differences in systolic left ventricular function in hypertensive patients with electrocardiographic left ventricular hypertrophy) the LIFE study). Am J Cardiol. 2001;87:980-983.

17. Celentano A, Palmieri V, Oberman A, Kitzman DW, Hopkins PN, et al. Gender differences in left ventricular chamber and midwall systolic function in normotensive and hypertensive adults. J Hypertens. 2003;21:1415-1423.

18. Gueyffier F, Boutitie F, Boissel JP, Pocock S, Coope J, Cutler J, et al. Effect of antihypertensive drug treatment on cardiovascular outcomes in women and men. A metaanalysis of individual patient data from randomized, controlled trials. Ann Intern Med 1997;126(10):761-767.

19. August P, Oparil S. Hypertension in women. $J$ Clin Endocrinol Metab 1999;84(6):1862- 1866.

20. Vasan RS, Beiser A, Seshadri S, Larson MG, Kannel WD, D'Agostino RB, et al. Residual lifetime risk for developing hypertension in middle-aged women and men: The Framingham Heart Study. JAMA 2002; 287:1003.

21. Safar ME, Smulyan H. Hypertension in women. Am J Hypertens. 2004;17(1):82-87.

22. Christou DD, Jones PP, Jordan J, Diedrich A, Robertson D, Seals DR. Women have lower tonic

I autonomic support of arterial blood pressure and less effective baroreflex buffering than men. Circulation 2005; 111(4):494-498.

23. Yusuf S, Sleight P, Pogue J, Bosch J, Davies R, Dagenaus G. Effects of an angiotensinconverting-

24. enzyme inhibitor, ramipril, on cardiovascular events in high-risk patients. The Heart Outcomes Prevention Evaluation Study Investigators. NEngl J Med 2000; 342:145.

25. Major outcomes in high-risk hypertensive patients randomized to angiotens in-converting enzyme inhibitor or calcium channel blocker vs. diuretic: The Antihypertensive and Lipid-Lowering Treatment to Prevent Heart Attack Trial (ALLHAT). JAMA 2002; 288(23):2981-2897.

African Health Sciences Vol 13 Issue 3 September 2013 